\title{
Theory into Practice: Using the PLUS Model to Teach Information Skills and Support the Curriculum in a Secondary School
}

\author{
James E. Herring
}

\author{
Head \\ Department of Information Management \\ Queen Margaret University College \\ Scotland
}

Anne-Marie Tarter

Librarian
Simon Naylor $\begin{array}{r}\text { Ripon Grammar School } \\ \text { England }\end{array}$
Teacher
England
Ripon Grammar School
This paper examines the use of PLUS, a four-step model of information skills, in a secondary
school in England with 28 Year 8 pupils doing a physics project. The pupils completed a
questionnaire relating to their use of the PLUS model and their attitudes to brainstorming,
keyword selection, evaluating resources, reading for information, taking notes, and writing. The
teacher and librarian were interviewed. Findings showed that pupils responded favourably to
using the PLUS model in all areas and that the teacher and school librarian noted improvement in
the pupils learning, writing, and information skills as a result of using the model.

\section{Introduction}

There has been a significant increase in the attention paid to the process of pupils' learning in secondary schools in recent years, and the importance of providing pupils with the necessary information skills to enable them to use effectively a range of print and electronic sources of information is now recognised in many countries across the world. This paper briefly reviews the literature on information skills (the term information literacy is also used) and identifies a number of models that exist in this field, particularly the PLUS model. The paper then describes a small-scale research project undertaken in Ripon Grammar School, Yorkshire,

England that focuses on the use of the PLUS model within the physics curriculum and that seeks to evaluate the views of the pupils, the teacher, and the school librarian on the applicability of this model within the secondary curriculum. The conclusions of the study identify the advantages and limitations of using a model such as PLUS in a secondary school's information skills programme and provide pointers for school librarians and teachers in other schools who seek to improve pupils' learning skills within the school curricular subjects.

A number of models have been proposed for school librarians and teachers to consider when implementing an information skills programme in their school. Marland (1981) presented the nine-step approach that identifies a series of questions that pupils might ask themselves when completing assignments. Eisenberg and Berkovitz (1990) offered the Big Six model that contains " six broad skills areas necessary for successful information problem solving." Kuhlthau (1994) 


\title{
Part V. Contributors
}

\section{Contributors to the Fourth International Forum on Research in School Librarianship}

\begin{abstract}
Abrizah Abdullah has worked in a number of schools as well as the Educational Policy Planning and Research Division. Ministry of Education in Malaysia. She is currently a Lecturer at the Faculty of Computer Science and Information Technology at the University of Malaya in Kuala Lumpur, Malaysia. Email: abrizah@fsktm.um.edu.my.
\end{abstract}

Marlene Asselin is a member of the Department of Language and Literacy Education in the Faculty of Education at the University of British Columbia, Canada. She coordinates the Diploma and Graduate Programs in Teacher-Librarianship, and her research areas of interest include reader response, resource-based learning, and the social dimensions of literacy. Email: marlene.asselin@ubc.ca.

Susan Gibson is Associate Professor in the Faculty of Education at the University of Alberta, Canada. Her ongoing research includes studies of collaborative research and the implementation and integration of the Internet into elementary and secondary schools. Email: sgibson@ualberta.ca.

Ken Haycock is Director of the graduate School of Library Archival and Information Studies at the University of British Columbia in Vancouver, Canada. He has been a teacher, teacher-librarian, and school principal as well as senior education official. From 1995-1997 he was the elected chair of the West Vancouver (Canada) School Board, and from 1995-2000 he served as Executive Director of the International Association of School Librarianship. Email: ken.haycock@ubc.ca

James E. Herring is Head of the Department of information Management at Queen Margaret University College, Scotland. He is the author of books and articles on school librarianship, information skills, and the use of the Internet in schools. He is currently researching the impact of school intranets on the role of the school librarian. Email: iherring@QMUC.ac.uk.

Eleanor B. Howe has served as librarian and taught in both elementary and secondary schools in the United States. Her interests include action research, implementing technology, and creating school library programs that contribute to the learning of students. She has published and presented articles and sessions at the local, state, national, and international levels. Email: howe@washington.k12.pa.us; ehowe@bellatlantic.net.

Jo-Anne Naslund is the Instructional Programs Librarian at the Education Library in the Faculty of Education at the University of British Columbia, Canada. She has worked as a teacher-librarian and a teacher of English and physical education. Her research interests include resource-based learning, reading interests, and children's literature. Email:

Joanne.naslund@ubc.ca. 
Simon Naylor, a physics teacher at Ripon Grammar School in England, has a keen interest in developing information skills in pupils who are studying science in secondary school. He is also active in developing instructional websites at the school. Email: simon.naylor@easynet.co.uk.

Dianne Oberg is Professor in the Department of Elementary Education, Faculty of Education at the University of Alberta, Canada. Her research interests include the use of libraries in schools, collaborative research, and the implementation and integration of the Internet into elementary and secondary schools. She also serves as editor of School Libraries Worldwide. Email: doberg@ualberta.ca.

Diljit Singh has taught in two schools as well as worked at the state and federal levels of the Ministry of Education. He is currently an Associate Professor at the Faculty of Computer Science and Information Technology at the University of Malaya in Kuala Lumpur, Malaysia. Email: diljit@fsktm.um.edu.my.

Gray Southon is Senior Lecturer in Knowledge Management in the Department of Information Studies at the University of Technology Sydney, Australia. He is engaged in two research projects exploring knowledge and the role of information professionals in organisations. Of particular interest are the dynamics of knowledge and how organisations create effective knowledge-sharing cultures. Email: Gray.Southon@uts.edu.au.

Anne-Marie Tarter, school librarian at Ripon Grammar School in England, has presented papers on information skills and the Internet in school libraries. She has also developed instructional websites, linked to the school library web pages, in her school. Email: tarters@globalnet.co.uk.

Ross Todd is Head of the Department of Information Studies at the University of Technology Sydney, Australia. He is engaged in two research projects exploring knowledge and the role of information professionals in organisations. Of particular interest are the dynamics of knowledge and how organisations create effective knowledge-sharing cultures. Email: Ross.Todd@uts.edu.au.

\section{Contributors to the Proceedings}

Claus Berg has since 1996 been in the Danish Ministry of Education working with the Sektornet," the national educational network in Denmark. He has also been a teacher who has been involved with Internet-based collaborative projects since 1990. He has spoken in Europe, South America, and the United States. Email: claus.berg@uvm.dk.

Kay Bishop has had over 20 years of experience as a school library media specialist and currently teaches courses in school media and youth services at the University of South Florida where she is also associate director of the School of Library and Information Science. Email: bishop kay@hotmail.com.

Margaret Butterworth worked in Singapore from 1980-84 as a librarian and from 199396 as Lecturer at Nanyang Technological University where she helped to establish a Masters course in librarianship. She is now completing a $\mathrm{PhD}$ at Curtin University and is an active member of the West Australian School Library Association. Email:

Margaret@iinet.net.au. 
developed a model that identifies how pupils feel during the assignment process as well as what they do, and Wray and Lewis (1995) presented a ten-stage model (EXIT) that focuses on pupils "interaction with the text."

The PLUS model (Herring, 1996) incorporates the key aspects of previous models and categorises information skills into 4 interrelated steps: Purpose, Location, Use, and Self-

Evaluation. The PLUS model provides a framework for pupils and teachers to use, but it is not seen as being only a linear model in which pupils work through each stage sequentially when completing an assignment. The PLUS model encourages pupils to identify purpose (e.g., brainstorm and map concepts), to locate relevant sources (e.g., search for and access print and electronic information resources), to use effectively the ideas and information found (e.g., read for information, take notes), and to reflect on their own information skills through self evaluation (e.g., evaluate their original plan or range of sources used).

\section{Research}

The research project in Ripon Grammar School was based on a Year 8 (age 13) science project in which pupils explored an aspect of sound technology by using their knowledge of the topic gained from classroom-based work with the science teacher as well as library resources such as books, journals, and CD-ROMs. Pupils had some limited access to the Internet, but using the Internet was not a requirement for this project. Working with the school librarian and the science teacher, the pupils were encouraged to use the elements of the PLUS model to

- plan their assignment with brainstorming and concept mapping,

- locate and evaluate relevant sources of information,

- read for information on their topic and take notes, and

- choose a form of presentation for their project.

The pupils worked in pairs on the project and used guides to key information skills in the form of handouts given to them by the school librarian.

\section{Questions and Methodology}

The methodology utilized a questionnaire (Leedy 1993; Silverman 1997) to answer the following research questions:

1. Did pupils find benefits in using brainstorming and concept mapping in their project?

2. Did pupils find that evaluating resources was a useful step in the process?

3. Did pupils find the identification of keywords useful when reading for information?

4. Did pupils find the PLUS model useful in structuring their approach to the project and in improving the quality of their work?

The views of the science teacher and the school librarian were elicited through semistructured interviews (Moore, 1983; Slater, 1990).

The discussion includes conclusions relating to the research questions, the limitations of the research with regard to its size and methodology, the relevant existing literature, and further possible research. 


\section{Findings}

Pupils' Opinions

With regard to planning their work by brainstorming, selecting keywords, and forming questions, the pupils overwhelmingly $(26 / 28)$ agreed that the PLUS model helped them to focus their work. The reasons given were varied, but the key factors identified were that planning with PLUS helped in

- searching for and finding information ("Because it helps you to actually find good information and to limit you to certain information.").

- identifying and organizing information ("I was able to sort out what I knew from what I didn't and find out what I needed to research"),

- forming questions ("Using keywords helped us to form questions and find the information"), and

- organising their work ("Because it helps you organize your work better; It made it easier later on.").

Two pupils did not agree, and one commented, "It didn't because we had to change it all after because we didn't get the right keywords".

All pupils agreed that "the initial planning made it easier to identify useful information" for their project. The pupils' comments were related to the ease with which they could identify relevant information when using books and other resources:

Because you only had useful information instead of non-useful.

Because you knew what to look for and not worry about what information to use.

The planning also helped them to use the keywords that they identified at the planning stage:

The keywords helped me find books.

Because you knew what words to look under.

Pupils also commented that the planning helped them quickly identifying subject headings in the library catalogue and that this saved them time.

In the project, pupils were asked to evaluate library resources before using them to take notes for their report. In the past, pupils had often complained about this step as an unnecessary hurdle to cross during the project. It was clear, however, that when the pupils looked back on this process at the end of the project, they overwhelmingly agreed that it was very useful for them to evaluate and choose resources before collecting information. One of the key reasons given was that this saved time at the next stage of the project:

When it came to writing up you knew exactly where to look, so you didn't waste time.

It saved time looking at useless information.

These remarks demonstrate that pupils could identify the links between the different stages of the project as well as the benefits they gained in terms of saving time and not reading 
irrelevant information when taking notes. The pupils also noted that this stage helped them to clearly identify relevant resources that related to the keywords they had previously chosen: "Because I saw which [resources] had the most information and understandable words that connected with my keywords." The pupils also found this process helpful in rejecting resources on the basis that they were not of the right standard: "Because some of the books were too simple and some were too complicated."

Pupils selected among different methods of recording information when they took notes from the resources: note cards, a grid, A4 paper, and "other methods" such as a concept map/spider diagram. Most pupils (16/28) favoured the grid method with note cards being the second most popular method (9/28). Four pupils used A4 paper and two used spider diagrams. Three pupils used more than one method. When asked why they preferred their chosen method, the pupils gave a wide variety of reasons. The main benefit to be seen from using their preferred method was that the information gathered was easy to read and find: "Because you can just skim over it to find the information you find useful." Pupils also agreed that, particularly with regard to the grid, the methods brought all the information together, and this facilitated both retrieval and organisation of notes:

\section{Because you know where all the information is [grid].}

\section{Because you can see all your ideas at once [grid and A4 paper].}

Using these methods, the pupils found it easier to organise the information they had gained from the resources:

\section{Because I could put them [note cards] in a suitable order for my topic.}

\section{Because you have questions and answers all organised.}

One pupil saw taking notes as a key step in the project process: "The note cards gave us the general idea and a grid really helped because it was the foundation for our project." Other comments related to pupil preferences, and one pupil stated that she used a spider diagram because that was the method she most liked. Another pupil found note cards the most useful "because they are small and handy; they keep all your information on them neat and tidy." Another pupil liked the grid "because you can cut it up and arrange your information." Thus the methods used by pupils varied, and it is clear that the pupils' reflection on their use showed an awareness of the process of doing a project as well as the subject content covered.

Pupils were encouraged to use a mental map to organise their ideas and notes before starting to write their project, and they were asked if using the map was useful. Most pupils $(22 / 28)$ used the map and found it to be very helpful. Six pupils did not use a mental map, but only two commented on the non-use, stating that they used an alternative method "because we decided to do it differently." The key benefit identified by pupils was that the mental map helped them to arrange their ideas effectively before writing:

Because I knew what order to put the information in.

Because you could plan all the information before you actually wrote it up on the computer and changed your mind.

Because I would have written the wrong things in the wrong place. 
Thus pupils were aware of the possible consequences, through previous experience, of not classifying and organising their ideas before writing. Other comments included "Because if I didn't [use the map] I would miss things out" and "Because it helped the presentation." There is clear evidence here of pupils being aware of the links between the different stages of the process of project work in that they are able to identify possible consequences if they fail to plan and organise their thoughts and their notes.

Pupils were asked whether they enjoyed using the PLUS method in their project, and most pupils (20/28) stated that they did. The reasons given were varied but did demonstrate the pupils' ability to review their methods of working and to draw conclusions from their experiences. The main reason for liking the PLUS model was its ease of use: "Because it's easy to use and you don't forget things." Pupils put equal value on the fact that the model allowed them to identify clear stages in the project process and this helped them to carry out their project in a logical manner:

Because you knew what to do next.

Because it meant that I did everything in the right order.

Because you do the project in stages rather than doing it all and getting mixed up.

One pupil stressed the importance of linking the different stages: "Because you can change it and make mistakes on your plan and you're not just looking for information and writing it up straight away." Another pupil recognised the value of the planning stages of the PLUS model: "Because there is quite a lot to do but it is a challenge and if you work hard at the beginning you are likely to get a reasonable mark." Those pupils who stated that they did not enjoy using the model had different reasons. One pupil found the model laborious: "I would have prepared most of it in my head." Two pupils found it boring and two other pupils preferred their own methods:

\section{I found it too restrictive.}

It isn't bad, I just like taking notes my own way.

Nevertheless, these pupils later stated that it did help them produce better work.

The pupils were then asked whether the PLUS model had helped them "produce better quality work," and the great majority of pupils (24/28) agreed. As above, there was a wide variety of comments from pupils, but most pupils agreed that using PLUS enabled them to be more organised in their approach to project work:

It's a more organised way of producing work."

Because I concentrated more because I had guidelines.

Pupils also appreciated the fact that using the model broke the process into stages and encouraged them to plan ahead:

Because we can think it through more instead of rushing into the project. 
It helped me because it made me do a step-by-step project.

Other pupils noted improvements in their own performances:

Because so far I have had better work using this method.

Because so far I haven't got that high a mark on a project.

Of the pupils who did not agree, two stated that other methods could have been used ("No, I think it would have been the same whichever way."), one pupil found the model confusing, and another stated, "No, the planning is better but I didn't make enough final notes." The latter pupil at least did learn from the self-evaluation part of the model.

Asked whether they would have made any changes in the way in which they worked during the project, 14 of the 28 pupils stated that they would not make changes. Of those who would have made changes, some argued that they would have found or included more information in their project:

I could have added more information.

Work a little faster and collect more information.

Other comments included a preference to work alone, a need to spend more time in the library, and a change of topic.

\section{The Teacher's Perspective}

The physics teacher thought that the PLUS method offered simplicity and flexibility and allowed the pupils to achieve successful leaming outcomes and to develop their independent research skills. The teacher stated that while many pupils can access large quantities of information they lack the expertise that will allow them to differentiate resources according to relevance and suitability. The structure of the PLUS method provided younger pupils with controlled access to information and helped to ensure that it was at a suitable level for their abilities. Careful lesson planning helped pupils to remain on task since many of the activities took less than 20 minutes. The structure becomes less teacher-driven as the pupils progress through the school, and they show a willingness to adapt the PLUS model into their own user-friendly version.

The teacher stated that it was essential to undertake pieces of research that are of manageable length within curricular time constraints. Many of the finished projects were shorter and less complex than those previously produced, but there was little doubt that plagiarism and cut-and paste projects were reduced to a negligible level. Moreover, the pupils understood the topic they had researched, and this had not always been the case with previous groups of pupils.

According to the physics teacher, information skills were now working their way through the school and all pupils were feeling the benefits of good research practice. The PLUS method could be adapted in the school by pupils and teachers without compromising the basics of the technique. Using the model had resulted in the pupils producing work that demonstrated how independent learning can serve their needs and talents in a world rich with information. 
The school librarian thought that the PLUS method incorporated the same general processes as other research models, such as Marland (1981), but that its strength lay in its simplicity. Pupils found the acronym PLUS and the steps for which the letters stand easy to understand and to remember. The school librarian believed that because it is easily remembered there is a much greater chance that the pupils will use PLUS in situations outside of the structured research lessons.

According to the school librarian, pupils used to working in a formal educational environment are often unsure of doing their own research, particularly when working in groups. The PLUS method's simplicity demystified the process of research and provided " a manageable roadmap that in our experience even the least confident pupil find accessible". The basic PLUS model can also be easily differentiated to match ability or age groups and has been used successfully in this school from Year 7 pupils (age 11) to Sixth Formers (age 17).

Pressure of the curricular timetable and demands upon the library mean that pupils do not always have a great deal of time in which to conduct their research. The PLUS method provided both pupils and staff with measurable targets to complete, and this encouraged efficient use of time and resources. The normal pattern for research was for three sessions in the library that correspond to the first three steps of PLUS. The final step of self-evaluation was completed in the classroom.

The school librarian argued that the use of any structured approach to research encourages pupils to produce their own work rather than merely copying facts with little or no understanding:

Since we have incorporated the PLUS method into the project work done in the library what we have found is that the work produced is often less complex than previously produced but is based more firmly on the youngsters' own understanding of the material.

This evidence of enhanced learning was the greatest testament to the success of the PLUS method in our school, in the school librarian's opinion.

\section{Conclusions}

It is clear from this study that the pupils doing this project greatly benefited from using the PLUS model. The pupils improved the way they planned their projects by brainstorming and identifying keywords. They evaluated resources before choosing which ones to use for their project. They identified clearly the links between the stages of the model; and they showed a good understanding of the way in which planning, location, use, and self-evaluation were integrated within their project work. The pupils constantly used the terms "sorting," "organising," "order," "ideas," and "information" ; and they demonstrated the ability to think about how the stages of the project related to each other while they were doing the project. Having completed the project, the pupils showed an ability to reflect on their own practice and that of their group. For most of the pupils, the PLUS model was seen as something that helped them in their approach to this project and provided a structure that enabled them to be, in their own words, "more organised"; and it is clear that the pupils saw the need to have an organised or structured approach to the project. This was partly due to the demands of the project, in that they had to complete a 
number of tasks, but this was also something that was stressed by both the teacher and the school librarian.

It is clear that a model such as PLUS does not suit all pupils, that some prefer their own methods, and that some pupils need much less guidance than others when completing a project. It is also clear, however, that the pupils benefited from being given a structure to work with. Whether some pupils would have imposed their own structure and still successfully completed the project was not investigated. Also, this investigation has examined pupils' use of the PLUS model, and the same pupils were not offered the opportunity to use other models. Thus the authors are not claiming that the PLUS model is superior to other models but rather that pupils do benefit from being given some model to work with. The other limitations to this research are that the research relates only to one school and one project with one group of pupils. Thus there is no attempt to generalise about either the usefulness of PLUS in other subjects in this school or in other schools. It should also be noted that this is a highly structured project, with pupils given much guidance from the teacher and the school librarian, and therefore no conclusions can be drawn in relation to other, perhaps less structured, projects which pupils might complete in the school.

Further research is being undertaken in the same school with Year 7 pupils (age 11) who also used the PLUS model while completing a science project, and it will be interesting to compare the results of the two projects in terms of the pupils' approach to the planning of projects and their use of information skills when using a range of information resources in the school. Another area of research that would be fruitful to investigate is the extent to which pupils learned from using PLUS in this project and applied the same skills when completing other projects in the school.

\section{References}

Eisenberg, M., \& Berkovitz, R. (1990). Information problem solving: The big six approach to library and information skills instruction. Westport, CT: Ablex.

Herring, J.E.(1996). Teaching information skills in schools. London: Library Association Publishing.

Kuhlthau, C. (1996). The virtual school library: Gateway to the information superhighway. Englewood, CO: Libraries Unlimited.

Leedy, P. (1993). Practical research (5th ed.). London: McMillan.

Marland, M. (Ed.). (1981). Information skills in the secondary curriculum. London: Methuen.

Moore, N. (1983). How to do research. London: Library Association Publishing.

Silverman, D. (1997). Qualitative research. London: Sage.

Slater, M. (Ed.). (1990). Research methods in library and information science. London: Library Association Publishing.

Wray, D., \& Lewis, M. (1995). Extending interactions with non-fiction texts: An exit to understanding. Reading, 29(1), 2-9. 